Prosocial and antisocial children's perceptions of peers' motives for prosocial behaviours.

Georgina Wardle, Simon C. Hunter \& David Warden.

\title{
Published:
}

Wardle, G., Hunter, S.C., \& Warden, D. (2011). Prosocial and antisocial children's perceptions of peers' motives for prosocial behaviours. British Journal of Developmental Psychology, 29, 396-408.

http://onlinelibrary.wiley.com/doi/10.1348/026151010X494296/abstract 


\begin{abstract}
This study investigated whether peer-nominated prosocial and antisocial children have different perceptions of the motives underlying peers' prosocial actions. Eightyseven children, aged 10- to 12-years-old, completed peer-nomination measures of social behaviour. On the basis of numbers of social nominations received, a subsample of fifty-one children (thirty-three who were peer-nominated as 'prosocial', and eighteen who were peer-nominated as 'antisocial') then recorded their perceptions of peers' motives for prosocial behaviours. Expressed motives were categorised predominantly into three categories coinciding with Turiel's (1978) 'moral', 'conventional', and 'personal domains'. Results indicate that children's social reputation is associated with the extent to which they perceive peers' prosocial motives as 'personal' or 'moral', with more prosocial children attributing moral motives, and more antisocial children attributing personal motives. Although traditionally Turiel's domain theory has been used to understand 'antisocial' children's behaviour, the current findings suggest that 'prosocial' children's behaviour may also be related to domains of judgment.
\end{abstract}




\section{Prosocial and antisocial children's perceptions of peers' prosocial motives}

Understanding how to promote prosocial behaviour in childhood is an important task for developmental psychology. In seeking a definition of prosocial behaviour, it must be recognised that prosocial behaviour may be enacted for different reasons, such as to achieve egoistic outcomes, ostensibly beneficial to the actor, or altruistic outcomes, ostensibly beneficial to others. Here, we adopt the definition used by Grusec, Davidov and Lundell (2002: 458), as 'any intentional action that produces a positive or beneficial outcome for the recipient regardless of whether that action is costly to the donor, neutral in its impact, or beneficial'.

As children grow older, prosocial behaviours become more important in terms of affiliation and social influence, while coercive and antisocial behaviours are tolerated less by their peer group (Hawley, 1999). The relative absence of prosocial behaviour, coupled with the presence of aggression, results in rejection by peers (Denham, McKinley, Couchoud, \& Holt, 1990; Volling, MacKinnon-Lewis, Rabiner, \& Baradaran, 1993), often leading to more frequent negative social interactions in adolescence (Dishion, Patterson, Stoolmiller, \& Skinner, 1991; Kupersmidt \& Coie, 1990; Tremblay, LeBlanc, \& Schwartzman, 1988; Hay, Castle, Davies, Demetriou, \& Stimson, 1999). In addition, interventions (such as Social Skills Training) can reduce levels of aggression while leaving levels of prosocial behaviour unchanged (Nangle, Erdley, Carpenter, \& Newman, 2002), highlighting that the processes underpinning prosocial and antisocial behaviours are distinct. Since behaviour in social situations is often based upon children's latent knowledge structures (Crick \& Dodge, 1994) we sought to clarify prosocial and antisocial children's understanding of the motives underpinning peers' prosocial behaviour. 
Knowing that something is 'right' or 'wrong' does not always elicit the 'right' or 'moral' course of action. Eisenberg (1986) claims that children who have developed the capacity to reason about what is 'right' may not necessarily choose to engage in prosocial behaviour because of, for example, a lack of motivation, the required skills, or adequate assertiveness. Furthermore, children's reasoning in different contexts, or relating to different concerns (for instance, egoistic or altruistic), may influence their subsequent prosocial behaviour (Eisenberg \& Fabes, 1998).

Developmental stage theories have been highly influential in informing our view of how children at various stages of development engage in reasoning and make social judgments. A helpful elaboration to this framework may be provided by Turiel's (1978) theory of domains of social judgment. Turiel (1978), and subsequently Nucci (1981), have demonstrated that when children make judgments about peers' negative social behaviours, they use consistent criteria in order to distinguish between categories of social knowledge (i.e., moral, conventional and personal) which motivate those behaviours. Children's domains of social judgment (Turiel, 1978) were investigated to address the concern that social competence as applied to aggressive behaviour tends to view such behaviour as 'value-free' and that moral issues, such as fairness and regard for others' welfare, have been ignored (Arsenio \& Lemerise, 2001). In addition, domains of social judgement link convincingly with other concepts associated with pro- and antisocial behaviour (e.g., Machiavellianism, see Sutton \& Keogh, 2000).

Turiel (1978) claims that moral judgments are seen to be obligatory, and not contingent on social or cultural rules. Judgments made in the moral domain are concerned with issues of welfare, justice, and rights. An example of a judgement in the moral domain might be that actions such as inflicting hurt, or the act of murder, 
for example, is always wrong, but consideration for the welfare of others is right, as it has the potential for positive outcomes. The moral domain involves actions which have inherently negative or positive outcomes. Context-dependent conventional judgments, on the other hand, are linked to existing accepted social arrangements, and, as such, are more arbitrary than moral judgments, since conventional actions do not involve inherently negative outcomes. An example of a judgment made in the conventional domain might be that it is not acceptable for a pupil to address his or her teacher on first name terms. It may be accepted convention for children to call their teachers by their surnames, but, even if children addressed their teachers by first names, there would be no inherently negative outcomes. By way of contrast, it is not possible to commit murder without causing inherent harm (Nucci, 2001).

Elaborating Turiel's theory, Nucci $(1981 ; 2001)$ has highlighted the existence of 'personal' judgments as those which are neither morally obligatory nor socially expected. Nucci (2001: 54) defines personal judgments as those which the 'individual considers to pertain primarily to oneself, and therefore, to be outside the area of justifiable social regulation'. The following examples may help to illustrate judgments made in the personal domain: the decision as to who would be one's best friends; or the decision to wear one's hair in a particular style; or the decision made by a college student to leave college, before completing his course, in order to pursue his own professional sports career, despite knowing that the college sports team depended on him for their only chance of success (Nucci, 2001; Turiel, 2002). According to Nucci (2001), the ability to make such personal choices is an important element in the identification of one's individuality, or social uniqueness, and in the development of the individual's sense of agency and autonomy. Importantly, the facility to develop a 
personal domain of privacy and discretion is necessary for healthy psychological growth (Nucci, 2001).

A fundamental concept of Turiel's (1978) theory is that children are able to make distinctions between domains of judgement: individuals derive social knowledge from their experiences, and they subsequently form conceptual systems which help them to interpret their varied social experiences. Turiel's (1978) theory does embrace developmental change in individuals' reasoning within the domains, but this change is of secondary importance to the existence of the domains themselves.

It has been further demonstrated (Nucci, 1981; Turiel, 1978) that individuals' negative behaviours in social situations are based on the judgments which they make in these three domains of social judgment. This being the case, similar categories of social knowledge (i.e., moral, conventional, and personal) may also underpin positive behaviours (Smetana, Bridgeman, \& Turiel, 1983). It has also been argued that an investigation into children's understanding of the ways in which actions are related to domains of judgment may provide an insight into the motivation behind children's prosocial behaviour (Smetana et al., 1983).

When considering effective social understanding, communication, and functioning, the ability to understand that other individuals have thoughts, or a 'mind' separate from one's own, is fundamental (Wellman, 1990; Baron-Cohen, 1995; Astington, 1996). However, the relationship between psychological understanding and social interaction is a complex one and the ability to interpret the thoughts and needs of others does not necessarily result in prosocial behaviour. Indeed, most children will engage in both prosocial and antisocial behaviour to a greater or lesser extent. 
In fact, a mature theory of mind may enable individuals to manipulate others for their own purposes (Sutton, Smith, \& Swettenham, 1999). However, it has also been shown that peer- nominated prosocial children have greater perspective-taking capacity than bullies (Warden \& Mackinnon, 2003). This finding suggests that children who demonstrate prosocial behaviour, and those who demonstrate antisocial behaviour, may differ in how they interpret the behaviours of others. Antisocial behaviour typically reflects direct and indirect aggressive actions, delinquent behaviour, and externalising (Crozier, Dodge, Fontaine, Lansford, Bates, Pettit, \& Levenson, 2008; Warden, Cheyne, Christie, Fitzpatrick, \& Reid, 2003). Children exhibiting such behaviour, especially aggression, tend to attribute hostile intent to peers' ambiguous actions (Dodge, 1980; Dodge \& Frame, 1982; Erdley \& Asher, 1996). This may reflect an understanding of the world where people are perceived to act for selfish or personal reasons rather than a view of the world which ascribes moral or conventional motives to the behaviours of others. Such an interpretation is given weight by Sutton and Keogh's (2000) findings that bullies have high Machiavellian scores, characterised by the manipulation of others for personal gain. Whether this extends to their interpretation of peer prosocial behaviours is at present unknown.

In contrast, prosocial behaviour involves acting in ways which will result in positive outcomes for others. Prosocial children are less likely than neutral children (i.e., children who are neither particularly prosocial nor antisocial) to attribute hostile intent to provocation by peers; rather, prosocial children are more likely to demonstrate a 'benign attributional bias', giving peers the benefit of the doubt in potentially provocative situations (Nelson \& Crick, 1999). Processing such as this may be characteristic of children who think that others act in accordance with moral 
or conventional rules, not only in provocative situations but also when actions are intended to have a positive outcome for others.

Theory relating to children's social information processing posits that children process social information through a series of steps which involve encoding and interpreting cues, clarifying one's goals, deciding on how to respond to cues, and evaluating potential alternative responsive behaviours (Crick \& Dodge, 1994).

It seems apparent that some children engage in positive behaviour towards others with the intention of manipulating them for selfish reasons. For instance, Sutton and Keogh (2000) have shown that aggressive children who display bullying behaviour and have high Machiavellian scores, are characterised by manipulative behaviour which serves their own purposes. Arsenio and Fleiss (1996) posit that proactively aggressive children lack the understanding that hurting others for personal gain is morally wrong, while MRI data from conduct disordered adolescents suggests that these young people may actually enjoy seeing victims in pain (Decety, Michalska, Akitsuki, \& Lahey, 2009). In a related vein, Menesini, Sanchez, Fonzi, Ortega, Costabile and Lo Feudo (2003) demonstrated that, compared with victims, bullies have a higher level of disengagement emotions and motives. Specifically, bullies showed high levels of egocentric disengagement, i.e., the bullies stressed positive personal advantages to be gained from bullying behaviour, and denied or distorted the consequences for the victim. Menesini et al. (2003) also reported that bullies appear to encounter some difficulty in perspective-taking in some situations.

Applying the domain model of motives, described above, to these types of antisocial behaviour, it appears that antisocial behaviour may be undertaken for personal, or selfish, rather than moral or conventional reasons. Given that aggressive children exhibit chronic biases in their patterns of social information processing 
(Arsenio \& Lemerise, 2001; Harvey, Fletcher, \& French, 2001) we sought to examine whether the processing of social interactions as falling within the personal domain dominates antisocial children's cognitions relating to prosocial as well as antisocial behaviour. Therefore, one aim of the current study was to investigate one relevant question which to date seems unexplored, i.e., whether the perception of others' motives for prosocial behaviour is affected by one's own prosocial or antisocial status. Antisocial ${ }^{1}$ and prosocial children may have different motivations for engaging in prosocial behaviour. Because of the importance of effective peer social interaction in preventing maladaptive behaviour (e.g., Dishion et al. 1991; Kupersmidt \& Coie, 1990; Tremblay et al., 1988; Hay et al. 1999), it is necessary to understand that some children may demonstrate antisocial behaviour as a result of misinterpreting underlying social cues.

Addressing this issue allows us empirically to integrate social domain theory with social information processing perspectives on children's behaviour. This enhances the latter by addressing concerns relating to the 'value-free' nature of processing within that model (Arsenio \& Lemerise, 2001). This study also brings fresh insights for social domain theory by examining it in relation to the perceptions of both prosocial and antisocial children. This understanding would also have practical implications for interventions designed to minimise children's negative behaviour. Specifically, results may inform CBT-type approaches to intervention (see Durlak, 1995) by highlighting attributions that may limit the extent to which positive behaviour is engaged in.

In the study of children's prosocial motives, one important area of investigation is the relationship between children's own behaviour and their perceptions of peers' prosocial behaviours. It may be the case that children who 
behave prosocially and antisocially have differing perceptions about peers' prosocial behaviour. On the basis of evidence that the social behaviour of aggressive children may be manipulative and selfishly-motivated (Sutton \& Keogh, 2000), it may be predicted that peer-nominated prosocial and antisocial children attribute differing motives to peers' behaviour.

\section{Aims and Hypotheses}

The aim of the current study was to examine whether the extent to which children engage in prosocial and antisocial behaviour is associated with their perceptions of the motives for peers' prosocial behaviour. On the basis of peernominations of prosocial and antisocial behaviour, prosocial and antisocial children took part in a computer task designed to assess their perceptions of the motives of other children involved in prosocial interactions. The possible motives suggested were related to aspects of Turiel's (1978) and Nucci's (1981) categories of social judgment, i.e., moral, conventional, and personal.

Aggressive children have been shown to access information from underlying social reasoning domains differently from their prosocial peers (e.g., Harvey et al., 2001). In the light of this finding, and also that aggressive children are inclined to display Machiavellian tendencies (e.g., Sutton \& Keogh, 2000), and are therefore concerned with their own needs rather than the needs of others, we predicted that antisocial behaviour would be positively related to the identification of personal motives for peers' prosocial behaviour. In contrast, because prosocial children show a tendency to view peers' behaviour through 'rose-colored glasses' (Nelson \& Crick, 1999), and give others the benefit of the doubt in provocative situations, it was also predicted that children with high prosocial scores would be more likely to ascribe moral and conventional motives to others. 


\section{Method}

\section{Participants}

Eighty-seven children (aged 11 years, 1 month to 12 years, 1 month; mean age 11 years, 6 months) from five same-level classes in three large suburban primary schools in West Central Scotland took part in peer nominations (see below). This sample comprised 50 boys and 37 girls. The schools were non-denominational and were maintained by the local authority. Permission was given by the local authority, head teachers of the schools involved, and by the children's parents or carers. On the basis of the peer nominations, a sub-sample of fifty-one children ( 24 boys and 27 girls) was identified. As children from different classes were involved, it was necessary to develop a standardisation method to take account of nomination frequency variations between classes. Ratings for the two behaviour categories, prosocial and antisocial, were therefore standardised across the sample and within individual classes, so that each child had a z-score indicating his or her position within the sample and a z-score indicating his or her position within the class. To be assigned to either category, children had to satisfy both parts of one of the following criteria:

A. (1) A z-score of .5 or more for sample ratings, and

(2) A z-score of above zero within their class

B. (1) A z-score of .5 or more for class ratings, and

(2) A z-score of above zero within the sample

Criterion A1 ensures that children who have overall extreme scores are selected, while Criterion A2 ensures that, in classes where the level of scores awarded is high for all pupils and scales, only those in the top half of the class are selected. Criterion B1 ensures that children who have high scores within a class are selected, but would, 
by itself, produce an equal proportion of prosocial and antisocial children in each class. Therefore, Criterion B2 ensures that pupils are only selected if their scores were in the top half of the sample. The combined use of these criteria ensures that children who have extreme prosocial or antisocial scores are allocated to the appropriate groups, but that any wide variation in scores across classes is taken into account (adapted from Warden, Cheyne, et al., 2003).

\section{Materials}

Peer nominations of prosocial and antisocial behaviour. All participants completed the Prosocial and Antisocial subscales of the Child Social Behaviour Questionnaire (CSBQ: Warden, Christie et al., 2003). Each subscale comprised eight items, with prosocial items tapping helping (e.g., helping with schoolwork), sharing (e.g., sharing snack with a child who has none), caring (e.g., being nice to a child who was sad or unhappy) and inclusion (e.g., sticking up for a child who was in trouble) behaviours, and antisocial items tapping physical (e.g., hitting or kicking another child) and verbal abuse (e.g., calling another child nasty names), delinquent (e.g., breaking another child's things) and rejecting behaviours (e.g., stopping another child from joining in a game) (Warden, Christie et al., 2003). In the current study, these two subscales demonstrated good internal reliability (Cronbach's alpha $=.90$ and .93 respectively). On each participant's questionnaire there appeared a random selection of ten male and female classmates' names. The lists of names presented were rotated across the participants to allow for each child's name being available for nomination 10 times for each of the 16 behaviours indicated.

Perceptions of peer prosocial motives. Through the use of 'Easy PHP' (2005) and 'Notepad' (2005), a computer program was developed and loaded on a laptop. The program was devised to gather data on the children's perceptions of the motives 
underlying a range of children's prosocial behaviours. The program involved a series of line-drawn pictures, accompanied by short written explanations (adapted from Warden \& Christie, 1997).

Two series of sixteen pictures were presented, one for boys, depicting boys behaving prosocially toward other boys, and one for girls, depicting girls behaving prosocially toward other girls. Same-sex only scenarios were presented deliberately to avoid attribution of 'romantic' motives (c.f. Greener \& Crick, 1999). Each series comprised four examples of each of the four prosocial behaviours of caring, inclusion, helping and sharing. The four examples of prosocial behaviour appeared in randomized order across each type of behaviour. Each series was preceded by the same four warm-up pictures which were designed to provide the participants with practice in using the seven-point likert scale.

The pictures were constructed so that, on the laptop screen, participants would be able to rate the likelihood of each of three motives, i.e. moral, conventional, or personal, as being the motive underlying the behaviour shown in each of the sixteen pictures. Underneath each of the sixteen pictures a short statement described the behaviour depicted in the picture, for example "Todd is a new boy at school. Billy is showing him the way to the dinner hall". Beneath each of these descriptions, three sentences were presented in random order, each with a corresponding seven-point likert scale. Each of the three sentences provided a motive of the actor in the picture, and were representative of considerations relating to the moral (e.g., "I feel sorry for Todd because he's a new boy at school and doesn't know the way to the dinner hall"), conventional (e.g., "We've been told that we should help new children in school”), and personal (e.g., "I want Todd to like me") domains. These scales had good reliability:.92 for both moral and conventional motives, and .96 for personal motives. 
Due to the constraints imposed by the computer program used, the scenarios were presented in the same order to all participants.

\section{Procedure}

Phase 1: Peer Nominations. Children were tested in small groups of four or six and it was explained that the purpose of the research was to investigate patterns of social behaviour, both positive and negative, by children towards others. Children were reminded that they did not have to take part in the activity, and that they were able to withdraw from the task if they wished. None chose to withdraw. Each child was then given his (her) own copy of the amended CSBQ, on which appeared the list of ten classmates' names. The children were reassured that all their responses would be confidential to the researcher alone, and they were then asked to indicate, next to the names on his (her) CSBQ, whether they had ever seen that child engaging in the range of behaviours described. They were instructed to indicate the frequency of their peers' observed behaviour ('never', 'sometimes', or 'often'). 'Sometimes' was defined as one to three occasions; 'often' was defined as on more than three occasions. It was specified that these sightings should have taken place during this term, and all within the school. When all the participants had completed the CSBQ task, the numbers of prosocial and antisocial peer nominations each child received were collated.

Phase 2: Perceptions of peer prosocial motives. Two weeks after the peer nomination process, the sub-sample of 51 children were withdrawn individually from their classes to a quiet area where the researcher explained the computer task, and the use of the likert scale, again stressing that responses were confidential. It was explained that the program consisted of four warm-up items and sixteen experimental items. For each warm-up item, the child would see a picture, underneath which was 
written a sentence explaining the action taking place in the picture. Underneath this there would be an additional, smaller, picture of one of the characters. This smaller picture would show 'thought bubbles' coming from the character's head. Beside this there would be written three possible 'thoughts', each of which could be potentially attributed to the character: it was explained these thoughts were related to the reason behind the behaviour shown in the picture. It was explained that the four warm-up items would help the child gain practice in using a seven-point type-type scale. The child was then shown how to start the program, and the researcher watched while the child worked through the four warm-up items. Following completion of the warm-up items, the researcher moved to another part of the room in order to give the child privacy to complete the task. Instructed by on-screen prompts, each child then worked through the experimental program consisting of sixteen items. The participants indicated the likelihood of each motive by clicking on the relevant point on the likert scale.

Children were assigned a Moral score, a Conventional score and a Personal score, depending on how they had rated these three motives for all the scenarios presented. There were sixteen scenarios, so possible scores for each motive ranged from 16 to 112 .

\section{Results}

Our aim was to investigate whether the extent to which children were prosocial or antisocial predicted Moral, Conventional, and Personal domain scores. To assess this, we used hierarchical, multiple regression. This was to examine the effects of prosocial and antisocial behaviour on children's domain scores, while also controlling for possible effects of gender and age. However, as outlined below, prosocial and antisocial scores were combined to create a single variable, meaning we 
had three predictors in our model. Field (2009) recommends that at least 40 cases (participants) are required to detect large effect sizes when there are three predictors in the model. To detect a medium effect, a sample of 80 is recommended when there are three predictors. This suggests our data set was powerful enough to detect medium-to-strong effects. Preliminary data screening indicated that Moral and Conventional scores were both significantly skewed, but for both sets of scores log transformations resolved this problem.

Inclusion of both the prosocial and antisocial nominations in our regression analyses (see below) resulted in a problem with multicollinearity $(V I F>3.58)$. The two sets of nominations were highly, negatively correlated $(r=-.85, p<0.001)$, and so we created a single measure by subtracting each child's antisocial nominations from their prosocial nominations. Higher scores on this measure therefore indicated a higher preponderance of prosocial than antisocial nominations, and we refer to this new variable as Social Reputation, with higher scores reflecting more prosocial than antisocial nominations, and low scores reflecting more antisocial than prosocial nominations.

Correlations between all the main study variables are shown in Table 1 . This shows that scores on the three domains were not significantly correlated, but that higher scores (more prosocial) on the Social Reputation measure were positively correlated with Conventional and Moral domain scores and negatively correlated with the Personal domain scores. We also checked to see if there were gender differences on the study variables by conducting independent t-tests. These indicated that girls $($ mean $=78.67, \mathrm{SD}=30.31)$ scored significantly higher than boys $($ mean $=34.41, \mathrm{SD}$ $=53.81)$ on both the Social Reputation measure, $t(49)=-3.67, p=.001$, and the Conventional domain scores (girls: mean $=0.54, \mathrm{SD}=0.26$; boys: mean $=0.39, \mathrm{SD}=$ 
$0.25), t(49)=2.10, p=.041$. Boys had significantly higher Personal domain scores $($ mean $=75.29, \mathrm{SD}=23.93)$ than girls $($ mean $=62.30, \mathrm{SD}=18.32), t(49)=2.19, p=$ .033. There were no gender differences on age and Moral domain scores.

Table 1 about here.

Three hierarchical, multiple regressions were conducted, one for each domain score (Moral, Conventional, and Personal). Each included age and gender as predictors at a first step, followed by the Social Reputation variable at a second step. Regarding personal domain scores, step 1 in the regression (including age and gender) did not together account for a significant portion of variance (see Table 2). Despite the overall model at step 1 being non-significant, gender was a significant individual predictor, indicating that boys had higher Personal domain scores than girls. Step 2 in the regression accounted for a significant portion of additional variance (9.6\%), and Social Reputation was negatively related to Personal domain scores, indicating that children with more prosocial nominations had lower Personal domain scores. For Conventional domain scores, Step 1 did not account for a significant portion of variance (see Table 3), though gender was again a significant individual predictor, with girls having higher Conventional domain scores than boys. Step 2 in the regression did not account for a significant additional portion of variance.

Tables 2 and 3 about here

Finally, for Moral domain scores Step 1 did not account for a significant portion of variance. Step 2 did account for a significant portion of additional variance 
(14.9\%). Social Reputation was positively related to Moral domain scores, indicating that children with more social reputations had higher Moral domain scores.

Table 4 about here

\section{Summary}

These results indicate that, after controlling for possible effects of gender and age, children's Social Reputations are associated with the extent to which they attribute peers' prosocial behaviour as due to Personal or Moral motives. A higher preponderance of prosocial peer-nominations was positively associated with Moral motives, but negatively associated with Personal motives. However, Social Reputations are not associated with the extent to which children attribute peers' prosocial behaviour as due to Conventional motives.

\section{Discussion}

In support of our hypotheses, children who engage in higher levels of prosocial behaviour are likely to identify Moral motives for peer prosocial behaviour, while those who engage in more antisocial behaviour are likely to identify Personal motives. However, we did not find support for the prediction that children who engage in higher levels of prosocial behaviour would also be more likely to identify Conventional motives for peer prosocial behaviour. Additionally, girls were significantly more likely to attribute Conventional motives, and less likely to attribute Personal motives, than boys were.

Our data indicate that, when faced with peers' prosocial behaviours, 'antisocial' children are more likely see Personal motives as underlying those behaviours. These results are congruent with evidence that antisocial children 
demonstrate Machiavellian attitudes (Sutton \& Keogh, 2000) in as much as they suggest that they have a tendency to believe others act prosocially only for relatively selfish reasons. Antisocial children, then, perceiving some sort of selfish motive, may respond to the prosocial behaviour of others in ways which may be seen as inappropriate. Prosocial children, on the other hand, tend to view the prosocial behaviours of others as being motivated by moral concerns. This inclination is likely to reduce the likelihood that they will consider prosocial behaviour to be enacted for anything other than some sort of positive motivation; they would not be likely to harbour suspicions about the intentions of others. Therefore, there appears to be scope for misinterpretation of prosocial motives by both antisocial and prosocial individuals. It appears that whereas prosocial children tend to give others the benefit of the doubt, antisocial children tend to be suspicious, and infer ulterior motives to others. Reasons for this difference in perception are not clear, but they offer support for the 'benign attributional bias' reported by Nelson and Crick (1999). We cannot say whether prosocial behaviour of prosocial and antisocial children themselves is actually motivated by different concerns, but it may be possible that children transfer their own motives to their perceptions of the motives of others.

Our results also relate to the notion that aggressive children display deficits and biases in their social information processing (Crick \& Dodge, 1994). Viewing moral domain-specific processing in this way, our results suggest that children who engage in lots of antisocial activity may be too quick to interpret the prosocial behaviour of peers as due to Personal motives, and too slow to view it as due to Moral motives. According to the social information processing model (e.g., Harvey et al., 2001; Fontaine, 2008), this deficit may then result in inappropriate and unwarranted aggressive behaviour towards unsuspecting peers. 
However, in the vignettes used in our study, the 'Personal' motives were limited in that they all described the fictional child as wishing to be popular or chosen as someone's friend. As noted earlier, the Personal domain involves a wide range of considerations motivated by personal discretion (Nucci, 2001) and so our measure may have been somewhat limited in focus. Antisocial children's focus on issues relating to popularity and friendship may thus reflect their documented rejection from the peer group (Denham et al., 1990; Volling et al., 1993) and the motivations behind their own attempts to interact positively with others. Perhaps this keen desire to be accepted results in clumsy attempts at engaging with peers and, when these fail, antisocial children resort or return to what they are most able at, i.e., aggressive and antisocial behaviour (Erdley \& Asher, 1996). Support for such a possibility comes from work showing that children who have moderate or high levels of stable aggression in childhood also have poor social skills (Campbell, Spieker, Burchinal, Poe, \& The NICHD Early Child Care Research Network, 2006), and are easily frustrated (Shields \& Cicchetti, 1998). To explore such a possibility, future research should examine whether a tendency toward making personal domain judgements relating to social behaviour is also related to children's social skills.

It is also notable that the more prosocial children actively preferred Moral motives. Hence, prosocial children seem to believe that peers act prosocially because those peers view the outcomes of such prosocial behaviour to be universally and intrinsically positive, rather than because they seek to gain some personal reward from the prosocial behaviour. Again, it may be suggested that prosocial and antisocial children both transfer their own motives to the ways in which they perceive the motives of others. Indeed, it is claimed (Sutton, Reeves, \& Keogh, 2000) that poor theory of mind performance in antisocial children is correlated with lack of remorse. 
This would suggest that antisocial children are less well-equipped to understand the needs and motivations of others. However, Arsenio and Lemerise (2001) argue that while aggressive children are variously seen as 'social inadequates' or as 'Machiavellian schemers', individual differences in emotion processes such as emotionality and emotion regulation may also contribute to differences found in empathy and social information processing skills of aggressive children. The findings of the current study highlight the importance of the claim of Arsenio and Lemerise (2001), that aggressive behaviour has traditionally been viewed as value-free, as the results suggest that children's behaviour which results in positive outcomes for others may be motivated by different values, not all of which are altruistic.

\section{Future research and limitations}

The current research has focused on perceptions of the prosocial motives of others, but an important line of future study is to investigate how prosocial and antisocial children evaluate their own motives for prosocial behaviour. Insight gained from this type of inquiry could inform the development of future intervention strategies designed to improve children's effective social functioning. A typical intervention strategy, for example, could be to help prosocial and antisocial children understand that peers may not share their perceptions of the motives of others. Lemerise and Arsenio (2000) have identified the importance of integrating research on the effects of emotionality and regulation (Eisenberg \& Fabes, 1998; Eisenberg et al., 1997; Hubbard \& Coie, 1994; Saarni, 1999) and cognitive decision-making (Crick \& Dodge, 1994; Dodge, Pettit, McClaskey, \& Brown, 1986) to children's social competence. Alluding to Turiel (1983), Arsenio and Lemerise (2001) have also raised the question of whether social competence can ever be regarded as 'value-free', and subsequently claim that in order to understand bullying and social competence, it is 
necessary to refer to traditional moral issues, such as fairness, the welfare of others, and avoiding personal reward gained through actions which may harm others. The findings of the current study help to support the stance (Arsenio \& Lemerise, 2001) that individuals' differing values are important in children's decisions to act prosocially. It would appear that intervention strategies which aim to reduce levels of children's antisocial behaviour should address questions such as shared and differing understanding of what is acceptable and unacceptable, and the negative consequences, to both individual and society, which may be suffered as a result of antisocial behaviour.

Future studies should also aim to consider these issues with larger sample sizes as the present sample was not large enough to detect small effect sizes. Our hypothesis that prosocial children would be more likely to identify Conventional motives which was not supported, though it was notable that in the relevant regression the association between Social Reputation and Conventional motives was in the expected direction (standardized beta $=.24$ ) and Social Reputation accounted for $4.5 \%$ of the variance in this motive. We therefore have confidence in our significant results, but are more tentative with regards to how conclusive our non-significant results are.

Given the scope of our measure relating to the personal domain (i.e., focussing on popularity and/or friendship building), future research should also aim to develop measure which more comprehensively capture the nuanced nature of cognitions relevant to this domain (c.f., Nucci, 2001).

\section{Conclusions}

Although stage theories of prosocial and moral reasoning provide a very helpful framework, useful for understanding the development of the capacity of 
prosocial and moral reasoning, they do not address individual decisions regarding the choice to act, or not to act, in a prosocial manner. Domain theory (Turiel, 1978, Nucci, 1981) is fundamental in explaining situational differences shown by individuals, but does not address the differences in judgments made by prosocial and antisocial individuals. The findings of this study not only support the idea that children engage in social reasoning in separate domains (Turiel, 1978, Nucci, 1981), but also show that peer-nominated prosocial and antisocial children perceive their peer prosocial motives differently. This study has revealed important relationships between the extent to which children are pro- or antisocial and the ways in which they judge peers' prosocial actions. Antisocial children tend to attribute Personal motives to peer prosocial behaviour, while prosocial children tend to ascribe Moral motives. 


\section{References}

Arsenio, W., \& Fleiss, K. (1996). Typical and behaviourally disruptive children's understanding of the emotional consequences of sociomoral events. British Journal of Developmental Psychology, 14, 173-186.

Arsenio, W., \& Lemerise, E.A. (2001). Varieties of childhood bullying: Values, emotion processes, and social competence. Social Development, 10, 59-73.

Astington, J.W. (1996). What is theoretical about the child's theory of mind?: A Vygotskian view of its development. In P. Carruthers and P.K. Smith (eds.), Theories of Theories of Mind. Cambridge, UK: Cambridge University Press (184-199).

Baron-Cohen, S. (1995). Mindblindedness: An essay on autism and theory of mind. Cambridge, MA: MIT Press

Campbell, S.B., Spieker, S., Burchinal, M., Poe, M.D., \& The NICHD Early Child Care Research Network. (2006). Trajectories of aggression from toddlerhood to age 9 predict academic and social functioning through age 12. Journal of Child Psychology and Psychiatry, 47 (8), 791-800.

Crick, N.R., \& Dodge, K.A. (1994). A review and reformulation of social information-processing mechanisms in children's social adjustment. Psychological Bulletin, 115, 74-101.

Crozier, J.C., Dodge, K.A., Fontaine, R.G., Lansford, J.E., Bates, J.E., Pettit, G.S., \& Levenson, R.W. (2008). Social Information Processing and cardiac predictors of adolescent antisocial behavior. Journal of Abnormal Psychology, 117 (2), 253267. 
Decety, J., Michalska, K.J., Akitsuki, Y., \& Lahey, B.B. (2009). Atypical empathic responses in adolescents with aggressive conduct disorder: A functional MRI investigation. Biological Psychology, 80 (2), 203-211.

Denham, S.A., McKinley, M., Couchoud, E.A., \& Holt, R. (1990). Emotional and behavioural prediction of preschool peer ratings. Child Development, 61, 11451152

Dishion, T.J., Patterson, G.R., Stoolmiller, M., \& Skinner, M.L. (1991). Family, school, and behavioural antecedents to early adolescent involvement with antisocial peers. Developmental Psychology, 27, 172-180.

Dodge, K.A. (1980). Social cognition and children's aggressive behaviour. Child Development, 51, 162-170.

Dodge, K.A., \& Frame, C.L. (1982). Social cognitive biases and deficits in aggressive boys. Child Development, 53, 620-635.

Dodge, K.A., Pettit, G.S., McClaskey, C.L., \& Brown, M.M. (1986). Social competence in children. Monographs of the Society for Research in Child Development, Serial No. 213, 51: 1-85

Durlak, J.A. (1995). School-based prevention programs for children and adolescents. USA: Sage.

EasyPHP (2005): Accessed at www.easyphp.org

Eisenberg, N. (1986). Altruistic emotion, cognition, and behavior. Hillsdale, NJ: Erlbaum.

Eisenberg, N., \& Fabes, R.A. (1998). Prosocial development. In W. Damon \& N. Eisenberg (eds). Handbook of child psychology $5^{\text {th }}$ Edition, Volume 4 (pp. 701778). New York: Wiley. 
Erdley, C.A., \& Asher, S.R. (1996). Children's social goals and self-efficacy perceptions as influences on their responses to ambiguous provocation. Child Development, 67, 1329-1344.

Field, A. (2009). Discovering statistics using SPSS. $3^{\text {rd }}$ Edition. London: Sage.

Fontaine, R.G. (2008). On-line decision making and antisocial behavior: Some essential but neglected issues. Clinical Psychology Review, 28, 17-35.

Greener, S.G., \& Crick, N.R. (1999). Normative beliefs about prosocial behavior in middle childhood: What does it mean to be nice? Social Development, 8, 350363.

Grusec, J.E., Davidov, M., \& Lundell, L. (2002). 'Prosocial and helping behavior.' in Smith, P.K., and Hart, C. (eds.), Blackwell Handbook of Childhood Social Development, 457 - 490. UK: Blackwell.

Harvey, R.J., Fletcher, J., \& French, D.J. (2001). Social reasoning: A source of influence on aggression. Clinical Psychology Review, 21 (3), 447-469.

Hawley, P.H. (1999). The ontogenesis of social dominance: A strategy-based evolutionary perspective. Developmental Review, 19, 97-132.

Hay, D.F., Castle, J., Davies, L., Demetriou, H., \& Stimson, C.A.(1999). Prosocial action in very early childhood. Journal of Child Psychology and Psychiatry 40 (6), 905-916.

Hubbard, J.A., \& Coie, J.D. (1994). 'Emotional correlates of social competence in children's peer relationships.' Merrill-Palmer Quarterly, 40, 1-20.

Kupersmidt, J.B., \& Coie, J.D. (1990). Preadolescent peer status, aggression, and school adjustment as predictors of externalizing problems in adolescence. Child Development, 61, 1359-1362. 
Lemerise, E.A., \& Arsenio, W. (2000). An integrated model of emotion processes and cognition in social information processing. Child Development, 71, 107-118.

Menesini, E, Sanchez, V. Fonzi, A., Ortega, R., Costabile, A., \& Lo Feudo, G. (2003). Moral emotions and bullying: A cross-national comparison of differences between bullies, victims, and outsiders. Aggressive Behavior, 29, 515-530.

Nangle, D.W., Erdley, C.A., Carpenter, E.M., \& Newman, J.E. (2002). Social skills training as a treatment for aggressive children and adolescents: A developmental-clinical integration. Aggression and Violent Behavior, 7, 169199.

Nelson, D.A., \& Crick, N.R. (1999). Rose-colored glasses: Examining the social information-processing of prosocial young adolescents. Journal of Early Adolescence, 19 (1), 17-38.

Notepad (2005): Accessed at www.notepad.org

Nucci, L. (1981). Conceptions of personal issues: A domain distinct from moral or societal concepts. Child Development, 52, 114-121.

Nucci, L. (2001). Education in the moral domain.UK: Cambridge University Press.

Saarni, C. (1999). The development of emotional competence. New York: Guilford.

Shields, A., \& Cicchetti, D. (1998). Reactive aggression among maltreated children: The contributions of attention and emotion dysregulation. Journal of Clinical Child Psychology, 27 (4), 381-395.

Smetana, J., Bridgeman, D.L., \& Turiel, E. (1983). Differentiation of domains and prosocial behaviour. In D.L. Bridgeman, The nature of prosocial development. Interdisciplinary theories and strategies, 163-181. New York: Academic Press. 
Sutton, J., \& Keogh, E. (2000). Social competition in school: Relationships with bullying, Machiavellianism and personality. British Journal of Psychology, 70, $443-456$

Sutton, J., Reeves, M., \& Keogh, E. (2000). Disruptive behaviour, avoidance of responsibility and theory of mind. British Journal of Developmental Psychology, $18,1-11$.

Sutton, J., Smith, P., \& Swettenham, J. (1999). Bullying and 'theory of mind: A critique of the 'social skills deficit' view of anti-social behaviour. Social Development, 8 (1), 117-126.

Tremblay, R.E., LeBlanc, M., \& Schwartzman, A.E. (1988). The predictive power of first grade peer and teacher ratings of behaviour and personality at adolescence. Journal of Abnormal Psychology, 16, 571-854.

Turiel, E. (1978). Social regulations and domains of social concepts. In W. Damon (ed.), New Directions for Child Development Vol 1 Social Cognition, 45-75. San Francisco: Jossey-Bass, 1978.

Turiel, E. (1983). The development of social knowledge. Morality and convention. UK: Cambridge University Press.

Turiel, E. (2002). The culture of morality. UK. Cambridge University Press.

Volling, B.L., MacKinnon-Lewis, C., Rabiner, D., \& Baradaran, L.P. (1993). Children's social competence and sociometric status: Further exploration of aggression, social withdrawal, and peer rejection. Development and Psychopathology, 5, 459-483.

Warden, D., \& Christie, D. (1997). Teaching social behaviour. London: David Fulton Publishers. 
Warden, D., Christie, D., Cheyne, B., Fitzpatrick, H., \& Reid, K. (2003). The Child Social Behaviour Questionnaire. University of Strathclyde, Glasgow.

Warden, D., Cheyne, B., Christie, D., Fitzpatrick, H., \& Reid, K. (2003). Assessing children's perceptions of prosocial and antisocial peer behavior. Educational Psychology, 23 (5), 547-567.

Warden, D., Christie, D., Kerr, C., \& Low, J. (1996). Children's prosocial and antisocial behaviour, as perceived by children, parents and teachers. Educational Psychology, 16 (4), 365-378.

Warden, D., \& Mackinnon, S. (2003). Prosocial children, bullies and victims: An investigation of their sociometric status, empathy and social problem-solving strategies. British Journal of Developmental Psychology, 21, 367-385

Wardle, G. A. (2007). Children's perceptions of peer prosocial behaviours and motives. Why are children nice to each other? Unpublished doctoral thesis. University of Strathclyde, Glasgow. UK.

Wellman, H.M. (1990). The child's theory of mind. Cambridge, MA: MIT Press.

Youniss, J. (1980). Parents and peers in social development. Chicago: University of Chicago Press. 


\section{Footnote}

${ }^{1}$ The authors acknowledge that, apart from in the most extreme cases, most children will engage in both prosocial and antisocial behaviour. In the current paper, the use of the terms 'prosocial' and antisocial' does not indicate that children have been formally or clinically classified as being either prosocial or antisocial. Rather, the children involved in the current study were identified by their peers as being more likely to behave in either a prosocial or an antisocial manner. 
Table 1.

Means, Standard Deviations, and Correlations of Main Study Variables.

\begin{tabular}{|c|c|c|c|c|c|}
\hline & 2 & 3 & 4 & 5 & Mean (SD) \\
\hline 1. Age in Months & -.06 & .01 & -.13 & .13 & $137.47(4.63)$ \\
\hline 2. Social Reputation & - & $-.42 * *$ & $.34 *$ & $.40 * *$ & $57.84(48.03)$ \\
\hline 3. Personal Domain & & - & .03 & -.26 & $68.41(21.93)$ \\
\hline 4. Conventional Domain ${ }^{1}$ & & & - & .23 & $0.47(0.26)$ \\
\hline 5. Moral Domain ${ }^{1}$ & & & & - & $0.48(0.27)$ \\
\hline
\end{tabular}

${ }^{1} \log$ transformed scores.

$* p<0.05$. ** $p<0.01$. 
Table 2.

Regression Analysis Predicting Personal Domain Scores from Gender, Age, and Social Reputation Score.

\begin{tabular}{llll} 
Step & Predictors & Step $1 \beta$ & Step $2 \beta$ \\
\hline 1 & Gender $^{\mathrm{a}}$ & $-.30^{*}$ & -.14 \\
& Age & -.03 \\
& & \\
$F(2,48)=2.38, p=.103, R^{2}=.090$ & $-.35^{*}$ \\
\hline $2 \quad$ Social Reputation & \\
$F_{\text {change }}(1,47)=5.55, p=.023, R_{\text {change }}^{2}=.096$ \\
\hline${ }^{\mathrm{a}}$ Gender coded $(1=$ male; $2=$ female $)$ \\
$* p<0.05$.
\end{tabular}


Table 3.

Regression Analysis Predicting Conventional Domain Scores from Gender, Age, and Social Reputation Score.

\begin{tabular}{llll} 
Step & Predictors & Step $1 \beta$ & Step $2 \beta$ \\
\hline 1 & Gender $^{\mathrm{a}}$ & $.30^{*}$ & .19 \\
& Age & -.15 & -.13 \\
& & \\
$F(2,47)=2.83, p=.069, R^{2}=.108$ & .24 \\
\hline $2 \quad$ Social Reputation & \\
$F_{\text {change }}(1,46)=2.45, p=.045, R_{\text {change }}^{2}=.045$ \\
\hline${ }^{\mathrm{a}}$ Gender coded $(1=$ male; $2=$ female $)$ \\
$* p<0.05$.
\end{tabular}


Table 4.

Regression Analysis Predicting Moral Domain Scores from Gender, Age, and Social Reputation Score.

\begin{tabular}{|c|c|c|c|}
\hline Step & Predictors & Step $1 \beta$ & Step $2 \beta$ \\
\hline \multirow[t]{2}{*}{1} & Gender $^{\mathrm{a}}$ & .13 & -.07 \\
\hline & Age & .12 & .16 \\
\hline \multicolumn{4}{|c|}{$F(2,47)=0.851, p=.434, R^{2}=.035$} \\
\hline 2 & Social Reputation & & $.44 * *$ \\
\hline \multicolumn{4}{|c|}{$F_{\text {change }}(1,46)=8.42, p=.006, R_{\text {change }}^{2}=.149$} \\
\hline \multicolumn{4}{|c|}{${ }^{\mathrm{a}}$ Gender coded ( $1=$ male; $2=$ female $)}$. \\
\hline
\end{tabular}

